\title{
Résumé des recommandations du CCI concernant les programmes d'immunisation contre le zona
}

\author{
Comité canadien sur l'immunisation ${ }^{1 *}$
}

${ }^{\star}$ Correspondance à : Secrétariat du CCl (cic-cci@phac-aspc.gc.ca)

\section{Introduction}

Le zona est causé par la réactivation du virus varicelle-zona et survient généralement de nombreuses années après la primo-infection. Le virus varicelle-zona est associé à la varicelle au cours de l'enfance et au zona chez les adultes. L'incidence globale du zona augmente au Canada, particulièrement chez les personnes âgées. Les personnes immunodéprimées présentent également un risque accru de contracter le zona. Le zona est caractérisé par une douleur neuropathique ainsi qu'un dermatome et comporte un risque cumulé pendant la vie entière de $15 \%$ à $28 \%$ au Canada. Les complications associées au zona surviennent dans $13 \%$ à $40 \%$ des cas. La complication la plus fréquente est la douleur, y compris la névralgie post-herpétique, une forte douleur durant plus de 90 à 120 jours après l'apparition de l'éruption cutanée. La névralgie post-herpétique a une incidence nuisible importante sur la qualité de vie et survient dans un tiers des cas de zona, après l'âge de 60 ans, le risque augmentant avec l'âge. En se basant sur les preuves scientifiques, le Comité consultatif national de l'immunisation (CCNI) recommande la vaccination contre le zona, pour la prévention du zona et de ses complications chez les personnes âgées de 60 ans et plus, qui ne présentent pas de contre-indication, ainsi que chez les personnes âgées de 50 à 59 ans. Le vaccin contre le zona n'est actuellement pas financé par les fonds publics au Canada. Ce document est un résumé du rapport complet du $\mathrm{CCl}$ en ce qui concerne les recommandations au sujet du zona (1). Recommandations pour les programmes d'immunisation contre le zona

\section{Objectif}

Déterminer si un programme de vaccination contre le zona, axé sur la population et financé par les fonds publics, peut être recommandé.

\section{Approche}

La déclaration du CCI s'est intéressée aux sujets suivants : caractéristiques et fardeau de la maladie, innocuité et efficacité du vaccin, stratégies et programmes de vaccination, faisabilité et acceptabilité, rentabilité, possibilité d'évaluer les programmes d'immunisation contre le zona, questions liées à la recherche et considérations en matière d'équité, d'éthique ainsi que politiques.

\section{Observations}

Zostavax ${ }^{\circledR}$ vaccin vivant atténué contre le zona aux fins d'utilisation au Canada chez les adultes âgés de 50 ans et plus, qui ne présentent aucune contre-indication. L'efficacité et l'innocuité de Zostavax ${ }^{\circledR}$ ont été démontrées dans le cadre de l'étude SPS (Shingles Prevention Study) et de sous-études connexes; la durée de la protection au-delà de sept années est incertaine, et les études sur 10 ans sont en cours.

L'administration du vaccin contre le zona peut être optimisée par la coadministration avec le vaccin contre le pneumocoque et la grippe chez les personnes âgées. Selon un examen d'analyses de rentabilité tirées de 12 publications provenant de sept pays, la rentabilité est maximisée lorsque le vaccin contre le zona est administré aux adultes âgés de 60 à 69 ans. La faisabilité d'un programme d'immunisation contre le zona peut être touchée par le besoin de congeler la préparation actuelle. Toutefois, il est actuellement projeté de rendre 
disponible au Canada une préparation stable au réfrigérateur à compter de mars 2014, qui améliorera probablement la faisabilité.

L'évaluation d'un programme d'immunisation contre le zona sera complexe, et de nombreux facteurs doivent être pris en compte, comme la disponibilité de systèmes qui permettent : 1) de mesurer la couverture vaccinale, l'utilisation et la qualité des vaccins; 2) de mesurer la réduction de l'incidence, des complications, des séquelles et des décès associés à la maladie; 3 ) de surveiller les événements indésirables associés à l'administration du vaccin, et 4) de relier les bases de données sur les résultats pour la santé, les registres d'immunisation et les registres de la population. La recherche en cours et prévue comprend des études menées sur des personnes âgées et immunodéprimées, des études portant sur un vaccin inactivé stable à la chaleur, et des études portant sur la durée de la protection. L'incidence à long terme des programmes d'immunisation contre la varicelle sur l'épidémiologie du zona peut faire l'objet d'études approfondies, portant également sur l'efficacité de la vaccination démontrée par une réduction des taux de la maladie, du fardeau de la maladie ainsi que des taux de névralgie post-herpétique.

\section{Recommandations}

Le $\mathrm{CCl}$ recommande l'administration courante du vaccin contre le zona aux adultes immunocompétents âgés de 60 à 65 ans, et aux personnes âgées ne présentant pas de contre-indications liées à l'épidémiologie du virus varicelle-zona, aux caractéristiques du vaccin contre le zona, à la modélisation de la maladie, ainsi qu'en fonction d'une analyse économique, de la faisabilité et de l'acceptabilité de programmes d'immunisation contre le zona. II n'existe aucun objectif national portant sur la prévention du zona au Canada, et l'établissement de tels objectifs guiderait la planification de programmes organisés. Faute d'un programme financé par les fonds publics, le vaccin est offert par achat privé.

\section{Référence}

Comité canadien sur l'immunisation. Recommandations concernant les programmes d'immunisation contre le zona. 2013.

http://publications.gc.ca/site/eng/464261/publication.html

${ }^{1}$ Remarque : Le Comité canadien sur l'immunisation offre des conseils d'ordre opérationnel et technique relatifs aux politiques et aux programmes d'immunisation au Canada. Le CCl est composé de représentants des provinces et des territoires, du Comité consultatif national de l'immunisation, du Advisory Committee on Immunization Practices aux États-Unis ainsi que de la Direction des produits biologiques et des thérapies génétiques, de la Direction des produits de santé commercialisés et de la Direction générale de la santé des Premières Nations et des Inuits de Santé Canada. 